\title{
The Computerphobia Reduction Program: Year 1. Program development and preliminary results
}

\author{
MICHELLE M. WEIL \\ Chapman College, Orange, California
}

and

\author{
LARRY D. ROSEN and DEBORAH C. SEARS \\ Califormia State University, Dominguez Hills, Califormia
}

\begin{abstract}
The program development and first-year results of a 3-year U.S. Department of Education Fund for the Improvement of Postsecondary Education (FIPSE) grant are described. The identification of computerphobics and the types of discomfort they experience are defined. A clinically based 5-week model computerphobia reduction and skills-acquisition program is presented. Screening and assessment measures are outlined and three treatment modules-two individual treatments (systematic desensitization and thought stopping) and an information/support group-are described. The first-year results demonstrate significant pretreatment-to-posttreatment change in anxiety, attitudes, cognitions, and feelings. Plans are discussed for further evaluation and program expansion.
\end{abstract}

Whether we call it "computer anxiety," "technostress," or "computerphobia," all estimates indicate that as many as one out of three adults suffers from aversive reactions to computers and computer-related technology. Studies of office secretaries, nurses, business managers, college students, school teachers, and educators indicate that a sizable minority have negative reactions to computers ranging from mild discomfort to severe debilitation.

These reactions are similar to those experienced by adults with anxiety disorders or phobias. Although two closely related disorders, test anxiety (Sarason, 1980) and math anxiety (Earnest, 1983; Richardson \& Woolfolk, 1980), have received extensive clinical study, no known attempt has been made to study and treat the computerphobic.

The Computerphobia Reduction Program is a 3-year demonstration project funded by the U.S. Department of Education's Fund for the Improvement of Postsecondary Education (FIPSE). Based on past research by Rosen, Sears, and Weil (1987) and others, FIPSE funded the computerphobia program in the fall of 1985. This report describes Year 1 of program development and the results of a longitudinal pilot study that assessed program effectiveness.

One reason computerphobia has been generally ignored to date is the misconception that experience alone is sufficient to "cure" the problem. Unfortunately, one of the symptoms of computerphobia is avoidance. The computerphobic banks only during banker's hours to avoid the computerized teller machines and purchases pushbutton kitchen appliances to avoid the technologically

Send reprint requests to: Michelle M. Weil, 615 E. Chapman Ave., Suite 200 , Orange, CA 92666. sophisticated programmable ones. Computerphobics do not buy VCRs or microwave ovens. The computerphobic student avoids courses that require computer interaction, or drops out during the semester, or remains and has extreme discomfort causing poor course performance.

The most common approach to computer-related discomfort has been to offer hands-on experience with userfriendly software. In a longitudinal study (Rosen et al., 1987), we examined the relationship between experience and computerphobia. Students who have taken a computer course do not have less computer anxiety than students with no course experience. Furthermore, after a 10-week course in which students used a computer an average of $4 \mathrm{~h}$ per week, anxiety remained unchanged, attitudes toward learning to use the computer became more negative, and physical discomfort increased. A study in progress at a major aircraft corporation demonstrated that $30 \%$ of the sampled employees became more computerphobic after a brief 4-day workshop on computer use.

Behavior theory explains that during repeated exposure to the computer, the computerphobic is being reconditioned at increased levels of anxiety, which, in turn, increases discomfort and avoidance. Thus experience appears to exacerbate computerphobia rather than cure the problem.

From both the research and the clinical perspective, computerphobia has had no common definition to date. In one recent attempt to synthesize the literature, Meier (1985) subsumed all definitions under the phrase "computer aversion," which he defined as "a negative affective reaction with concomitant behaviors and cognitions" (p. 171). Under this definition he further specified three specific psychological reactions to the computeropposition, apprehension, and fear. For each reaction he 
suggested potential intervention strategies that may include repeated computer exposure, skills training, information presentation, and clinically based techniques. Our approach is similar to Meier's in that we define three computerphobia problem areas. Unlike Meier, however, we believe that simple computer exposure is detrimental to the computerphobic. Instead, all interventions are clinically based.

Based on extensive research with university students, we have identified three overlapping areas of computerphobic discomfort: (1) anxiety toward computers; (2) negative thoughts, attitudes, and feelings toward computers; and (3) lack of information or presence of misinformation about computers and computer-related technology. We also have encountered a fourth type of computerphobic reaction from students with more general psychological problems. Although their discomfort is not directly related to computers, they exhibit it during computer interaction, as well as in other areas of their lives.

The Computerphobia Reduction Program is geared toward assessing which specific area or areas are problematic for the individual and then tailoring the treatment to the individual's need. The following section briefly describes the entire program, including screening and assessment, individualized programs, and training of paraprofessional counselors. The final section describes the results of the Year 1 longitudinal pilot study and future program directions.

\section{SCREENING AND ASSESSMENT}

Students are recruited primarily from courses in which computer interaction is required (e.g., programming, report writing, word processing, test taking, statistical analysis). Each student in the course is administered a brief assessment (10-15 min) that includes the Computer Anxiety Rating Scale (CARS) and the Computer Thoughts Survey (CTS) (see Rosen et al., 1987, for an extensive review of the creation and validation of these measures). The CARS is a 54-item self-report measure of perceived anxiety about computers, their role in society, computer programming, computer interaction, and consumer use of computers. For research purposes the CARS has 12 identifiable subscales that highlight anxiety about various aspects of computers and computer interaction. For clinical purposes, empirical evidence has provided three clear groupings that designate whether the student is at risk for computerphobia: high anxiety, moderate anxiety, or low anxiety.

The CTS is a 28-item self-report measure of cognitions and feelings during real or imagined computer interaction. Items represent a range of potential negative thoughts ("I'll never be able to figure this out," or "I'll probably damage the machine by pushing the wrong button") and positive assertions ("This will be fun") that are each rated by frequency of occurrence. For clinical purposes, three at-risk groups can be identified: extremely negative, moderately negative, or slightly negative.

Following the assessment, the students receive a personal computer comfort profile that indicates whether they belong to any of the anxiety or negative-thoughts risk groups. All students, regardless of their assessment findings, are invited to contact the program staff for further information. Upon contact, the student receives a clear description of the program and its goals. The goal of all programs is to help remove the psychological barriers to comfortable and confident computer interaction. The skills acquired in the program are psychological in nature and are applicable to a wide array of technologybased discomfort.

Special care is taken to explain that the program is not a class, a seminar, or a computer tutorial and to clarify any other misconceptions the student may have. The interested student signs an informed consent indicating that he/she understands the program, the assessment procedures, and their purpose. Each student also completes the Attitudes Toward Computers Scale (ATCS; Rosen et al., 1987), a 26-item Likert-type scale that assesses level of agreement toward general attitudes about computer usage, future job prospects, societal power, and computer control.

Additionally, each student completes the Minnesota Multiphasic Personality Inventory (MMPI; Hathaway \& McKinley, 1951), a paper-and-pencil instrument that is used as a screening device for evidence of general psychological problems. Because our campus serves a nontraditional student population that includes many black students, we also use a correction factor developed by White (1974) to indicate the extent to which a black student deviates from the modal performance of the predominantly white normative MMPI sample.

Finally, the student completes the confidential intake form that includes: (1) demographic data, including age, gender, ethnic background, academic major; (2) selfreported computer anxiety, computer attitudes, computer knowledge, and computer confidence; (3) self-reported symptoms of physical discomfort when interacting with computers; and (4) self-reported negative thoughts when interacting with computers.

\section{TREATMENT PROGRAMS}

Depending on the assessed level and type of discomfort, students are assigned either to one or two of the three skills-acquisition modules: (1) an individualized relaxation training and systematic desensitization program, (2) an individualized cognitive-behavioral thoughtstopping and covert-assertion program, or (3) an information/support group. Any student who shows evidence of general psychological difficulties is referred to the Student Counseling Center, since specific computerphobia reduction treatment may not provide the comprehensive assistance needed. The senior author is a licensed clinical psychologist, and she interprets the assessment data and makes the treatment assignments.

Systematic Desensitization (SD), developed by Wolpe (1958), has been used to treat a wide variety of phobias including test-taking and math phobias (Allen, Elias, $\boldsymbol{\&}$ Zlotlow, 1980). SD alleviates maladaptive anxiety through counterconditioning. Initially, the client is taught to re- 
lax completely. After learning relaxation skills, the client progressively pairs the relaxation response with a hierarchy of imagined scenes depicting increasing levels of interaction with his/her feared object or situation. As the client progresses through the hierarchy (learning to relax in situations that previously caused anxiety and avoidance), the client is able to approach and interact with the previously feared object or situation. Therefore, approaching and interacting with the computer in real life will be accomplished in an efficient and timely manner once the client's anxiety and ensuing avoidance has decreased and been replaced by relaxation. Table 1 presents a sample hierarchy utilized by a computerphobic with high anxiety.

Since computerphobia is a newly identified problem, all hierarchies are individually tailored. As this project progresses, it is hoped that we will identify a "commontheme" hierarchy that can eventually be utilized in a group SD procedure. This will enable future programs to utilize personnel and time more efficiently, as well as to help more people learn the necessary skills.

Thought stopping and covert assertion (Rimm \& Masters, 1979) are cognitive-behavioral treatments that focus on the client's faulty internal dialogue. In the highly self-critical individual, the internal dialogue is selfdefeating and negative rather than task-oriented and positive. The individual's negative self-statements create anxiety and low self-esteem and lead to avoidance. Thought stopping is a technique to help the client not only identify the self-defeating messages, but to stop the messages internally. Once the client has learned to stop negative thoughts, an internal "void" is left. Next, covert assertion helps the client create positive, motivating selfstatements and internalize them to fill the void. Thus, when a computerphobic stops the negative, avoidance-

Table 1

Sample Hierarchy of Anxiety-Producing Scenes for Systematic Desensitization

\section{Least Anxiety Producing}

1. Noticing a newspaper advertisement for a computer.

2. Looking through a college catalog at the computer courses offered.

3. Hearing the beeping noises the computer at home makes when the children are playing.

4. Sitting in a computer class the first day and hearing about the assignments that must be completed.

5. Having a friend help you on a computer assignment.

6. Working in the computer room on a computer assignment that is due in two weeks.

7. Having your children ask you to help them figure out a computer homework problem.

8. Getting an error message while working on a computer assignment and not knowing where the problem lies.

9. Having a class assignment due in one hour and having no one to help you if you can't figure it out.

Most Anxiety Producing
Table 2

Sample Negative Thought/Covert Assertion Pairs

\begin{tabular}{ll}
\hline \multicolumn{1}{c}{ Negative Thought } & \multicolumn{1}{c}{ Covert Assertion } \\
\hline I don't understand this! & I can figure this out! \\
This is too much to handle! & I enjoy the challenge! \\
I hope that I have enough & Relax, take your time.
\end{tabular}

time!

Everyone else knows how to

do this!

I feel stupid!

If others have learned this, so can I!

This is enjoyable and exciting!

I'm going to make a mistake.

I am an intelligent and capable person.

What if I hit the wrong

I know I can do it!

button?

creating thought (e.g., "I just can't understand this thing') through thought stopping, he/she might replace it by a covert assertion (e.g., "I'm smart enough to use this computer!'), motivating approach and interaction with the computer. Like SD, thought stopping has been used in treating a variety of anxiety disorders, including test anxiety (Denney, 1980) and math anxiety (Earnest, 1983). Table 2 presents examples of negative thought/ covert assertion pairs.

The information/support group is designed to impart specific information about computers while providing a supportive environment in which to share feelings, thoughts, and concerns. One goal of the group is to promote a feeling of universality for the computerphobic, a feeling that he/she is not alone. The group design is partly structured and partly unstructured to help participants feel at ease while allowing room for self-disclosure, discussion, problem solving, and skills-acquisition. Each group meeting has a specific goal with one or two group exercises aimed at accomplishing that goal. Each exercise encourages participation from all members and is aimed at motivating each member in a comfortable environment while teaching certain information and skills (see Table 3 for group goals).

All modules require 5 total hours spread over 5 weeks. The information/support group meets once a week for $1 \mathrm{~h}$, whereas each individual program meets twice a week for $.5 \mathrm{~h}$. This schedule allows sufficient time for acquiring, practicing, and internalizing the skills in all three modules. It also makes it possible for a student to participate concurrently in one individual module and the group module.

All modules conclude with a component that allows students an opportunity for hands-on interaction with the computer while composing and printing personalized graduation certificates declaring them "computer confident!" This unique opportunity allows the participants to utilize their newly acquired skills while noting the changes that they have made during the program. The certificate then becomes a permanent reminder of their success. 
Table 3

Session-by-Session Goals for the Information/Support Group

Session 1: "Myths and Realities About Technology"

Goal: To acquaint clients with one another and the group leader, to begin to establish cohesion and universality, to help clients clarify their ideas about what computers can and cannot do, to help clients gain a more realistic picture about computers and increase their comfort level.

Session 2: "Fears and How to Stop Them"

Goal: To help clients identify the fears that cause discomfort and gain practical experience in dispelling these fears.

Session 3: "Computer Technology in Your Future"

Goal: To help clients clarify what they want from computer technology in their immediate and long-term future; to help them identify what gets in the way and then problem-solve those issues.

Session 4: "Things that Go Bump in the Night"

Goal: To help clients clarify their fears about the "guts" of the computer, learn how different it is from their imaginings, and discover how their fantasies get in their way.

Session 5: "Summary and Closure"

Goal: To summarize what the group sessions have addressed and give clients the opportunity to discuss what they have learned.

\section{INTERNSHIP TRAINING PROGRAM}

An important aspect of the Computerphobia Reduction Program is that all skills-acquisition modules are delivered by student interns chosen from a number of clinically based master's degree programs (e.g., clinical psychology; community psychology; marriage, family, and child counseling). Selection is based on experience, time availability, and interest and commitment in the 1-year internship placement.

All interns are trained in a group format with extensive use of videotape viewing of clinical sessions, role playing practice, and readings from clinical literature. The training requires 5 half-day workshops that include office procedures, assessment and screening, SD, thought stopping and covert assertion, information/support group sessions, and termination procedures. Each intern receives weekly individual supervision that includes videotape viewing of selected sessions. Weekly group supervision provides additional ongoing support and learning opportunities through discussion of common issues and concerns.

\section{LONGITUDINAL PILOT STUDY RESULTS}

During the first half of Year 1, the skills-acquisition modules were developed and tested on 2 individuals by the senior author. Two interns were then trained to deliver the modules, and each worked with 6 students as a pilot study for the entire program. Of those, 4 students received only an individual module (2 each received SD and thought stopping), 8 students participated in both individual and group modules (6 in thought stopping and 2 in SD), and 2 students participated in a group module only. Of these, 11 were female with a mean age of 42 years, and 3 were male who averaged 30 years of age. Eight of the 14 were white.

All students were given a posttreatment assessment that included the same instrument package as the pretreatment assessment, without the MMPI. (Note: Five students completed the program before the CTS was created and validated, so pre- and posttreatment CTS data are only available for 9 students.)

Because of small sample sizes in each module, data were analyzed across treatments. Table 4 displays pre- and posttreatment data for all self-report and computerphobia measures. First, it is clear that participants changed significantly on all measures. On two of the three computerphobia measures, every student changed in the positive direction (less anxiety; more positive thoughts), whereas on the third, 13 of 14 had more positive attitudes after the program. Computer anxiety scores dropped over 50 points, and 10 students changed from a risk group to a no-risk group (6 high-anxiety, 1 moderate-anxiety, and 3 low-anxiety students became nonanxious). Two other students reduced their high- and moderate-anxiety risk to low-anxiety risk. Although the majority began with attitude scores that indicated no risk, 5 changed from risk to no risk and 1 from extremely negative to negative attitude. On the CTS, 6 of the 9 clients changed from risk groups to no risk and 2 more from extremely negative thoughts to only slightly negative thoughts. Overall, 10 of the 14 clients completed the program showing no risk on any of the three scales.

Self-ratings also indicated change. Students completed the program having a more positive attitude, feeling less computer anxious, showing more computer confidence,

Table 4

Pre- and Posttreatment Comparison of Self-Report and Instrument-Generated Measures for All Skills-Acquisition Modules in the Computerphobia Reduction Program (Year 1)

\begin{tabular}{|c|c|c|c|c|}
\hline \multirow[b]{2}{*}{ Measure } & \multicolumn{2}{|c|}{ Means } & \multirow[b]{2}{*}{$t$ Score } & \multirow{2}{*}{$\begin{array}{c}\text { Percent with } \\
\text { Positive Change }\end{array}$} \\
\hline & Pre & Post & & \\
\hline \multicolumn{5}{|l|}{ Instruments } \\
\hline CARS & 142.21 & 86.71 & $6.73^{*}$ & 100 \\
\hline ATCS & 77.50 & 90.35 & $-2.69 \dagger$ & 93 \\
\hline CTS $\ddagger$ & 78.56 & 106.43 & $-9.99 *$ & 100 \\
\hline \multicolumn{5}{|l|}{ Self-Ratings } \\
\hline Knowledge & 3.20 & 4.14 & $-4.14^{*}$ & 79 \\
\hline Attitude & 2.29 & 3.50 & $-5.84^{*}$ & 79 \\
\hline Anxiety & 3.07 & 2.32 & $3.88 \dagger$ & 64 \\
\hline Confidence & 2.68 & 3.86 & $2.94 \dagger$ & 71 \\
\hline Physical Discomfort & 1.86 & .64 & $3.88 \dagger$ & 71 \\
\hline
\end{tabular}

Note-Self Rating Scales: Knowledge $(1=$ much lower than average; $5=$ much higher than average); Attitude ( $1=$ very negative; $5=$ very positive); Anxiety ( $1=$ very low; $5=$ very high); Confidence $(1=$ very low; $5=$ very high); Physical Discomfort $(0=$ no symptoms to $5=$ all symptoms). $\quad{ }^{*} p<.001 . \quad \dagger p<.01 . \quad \neq n=9$; for all other scores, $n=14$. 
displaying fewer self-reported signs of physical discomfort when interacting with computers, and feeling more knowledgeable about computers in general.

Anecdotal evidence indicates that program benefits have generalized to other areas in the participants' lives. It seems that once learned, the skills are highly generalizable, and the participants quickly begin applying their skills to other previously uncomfortable areas. A typical participant in the SD module proudly noted that she had become so calm and relaxed that she discovered hours of extra time that she used to spend worrying. One thought stopping participant has used his skills to become more outspoken. Before he took the program, asking questions or volunteering information in class was a frightening experience. After the program, he began to covertly assert his right to participate and speak in class.

As an integral part of the evaluation procedure, we are currently recontacting each participant 6 months after treatment completion and assessing the longitudinal program impact.

\section{FUTURE DIRECTIONS}

The Computerphobia Reduction Program provides several brief treatments for a variety of computerphobia problem areas. The participants receive a solid, wellconstructed skills-acquisition program that has generalizability to many areas of their lives. Within a very short time frame, their computerphobia problems can be resolved and they can approach technology in a clear, confident manner.

During the next 2 years, the program will be expanded to include a larger population of faculty, staff, and students. We will increase campus awareness of our pro- gram and seek out additional avenues to contact the computerphobic individual. Our continued efforts at outreach will also be aimed at becoming better known through local and national news media and professional and public speaking. The long-term goal is to disseminate the model program in "package form" such that it can be implemented on other university and college campuses nationwide.

\section{REFERENCES}

Allen, G. J., Elias, M. J., \& Zlotlow, S. F. (1980). Interventions for alleviating test anxiety: A methodological overview of current therapeutic practices. In I Sarason (Ed.), Test anxiety: Theory, research, and applications. Hillsdale, NJ: Erlbaum.

DENNEY, D. R. (1980). Self control approaches to the treatment of test anxiety. In I. Sarason (Ed.), Test anxiety: Theory, research, and application (pp. 209-243). Hillsdale, NJ: Erlbaum.

EARNEST, J. (1983). Math anxiety: A cognitive approach. Unpublished manuscript, Nassau Community College, New York.

Hathaway, S. R., \& MCKinley, J. C. (1951). The MMPI manual. New York: Psychological Corp.

Meier, S. T. (1985). Computer aversion. Computers in Human Behavior, 1, 171-179.

Richardson, F. C., \& Woolfolk, R. L. (1980). Mathematics anxiety. In I. Sarason (Ed.), Test anxiety: Theory, research, and applications (pp. 271-288). Hillsdale, NJ: Erlbaum.

RuMm, D. C., \& MASTERS, J. C. (1979). Behavior therapy: Techniques and empirical findings (2nd ed.). New York: Academic Press.

Rosen, L. D., Sears, D. C., \& WeIL, M. M. (1987). Computerphobia. Behavior Research Methods, Instruments, \& Computers, 19 , 167-179.

SARASON, I. (Ed.). (1980). Test anxiety: Theory, research, and applications. Hillsdale, NJ: Erlbaum.

WHITE, W. G. (1974). A psychometric approach for adjusting selected MMPI scale scores obtained by Blacks. Unpublished doctoral dissertation, University of Missouri, Columbia.

WOLPE, J. (1958). Psychotherapy by reciprocal inhibition. Stanford, CA: Stanford University Press. 